\title{
Extracção em Fase Sólida (SPE): II. Mecanismos de Extracção
}

\author{
FERNANDO RAMOS, MARIA DA CONCEIÇÃO C A STILHO \\ e MARIA IRENE NORONHA DA SILVEIRA*
}

\begin{abstract}
Neste trabalho sâo apresentados os principais mecanismos de extracção de SPE, particularmente as interaccōes que são estabelecidas entre enchimento/ analito, analito/matriz e matriz/ enchimento.
\end{abstract}

\section{INTRODUÇÃO}

O presente trabalho constitui a segunda parte de uma revisão sobre SPE e nele são apresentados os principais mecanismos de extracção, após abordagem, num primeiro artigo, dos tipos de enchimento utilizados nesse processo [1].

Em SPE, o processo de extracção está intimamente ligado às características do analito, do enchimento e da matriz pelo que, fundamentalmente, será em torno destes três aspectos que desenvolveremos a nossa revisão.

\section{MECANISMOS DE EXTRACÇÃO}

A compreensão dos diversos mecanismos de extracção que ocorrem em SPE é, muitas vezes, complexa. Nesse sentido, e por uma questão de sistematização, vamos restringir-nos unicamente aos mecanismos relativos aos movimentos do analito através do enchimento. Para isso importa, primeiro, definir alguns conceitos importantes como sejam retenção, eluição, capacidade e selectividade.

Assim, retenção é o fenómeno resultante da atraç̧ão existente entre o enchimento e o analito originando a imobilização deste na superfície daquele. A retenção depende de três factores: do analito, do solvente e do enchimento. As propriedades de retenção de um dado analito não são sempre as mesmas podendo ser modificadas na presença de diferentes solventes ou enchimentos.

A eluição é o processo pelo qual um analito é removido do enchimento onde está retido, devendose, para isso, utilizar um solvente que possua maior afinidade para o analito do que o enchimento onde este se encontra retido.
Na cromatografia clássica são também aplicados os termos retenção e eluição. No entanto, quando comparamos os objectivos de SPE com os da cromatografia verificamos que são distintos. Enquanto na cromatografia o processo de retenção /eluição ocorre simultaneamente, em SPE acontece em dois tempos distintos. Aliás, um dos objectivos de SPE pode ser, mesmo, reter o analito de forma a que este não se mova pelo leito do enchimento até que o eluente seja introduzido no sistema.

A unidade de medida mais correntemente utilizada para caracterizar a retenção e a eluição em SPE é o volume do leito que pode ser definido pela quantidade de solvente necessária para preencher todos os poros e espaços intersticiais das particulas do enchimento. Por exemplo, para particulas com $40 \mu \mathrm{m}$ de tamanho e $60 \AA$ de poro, o volume do leito é da ordem dos $120 \mu \mathrm{L}$ por cada $100 \mathrm{mg}$ de enchimento. Assim, considera-se que a retenção é suficientemente forte quando o equivalente a 20 vezes o volume do leito de um solvente de lavagem adequado passa pelo enchimento sem eluir o analito enquanto uma óptima eluição não deve necessitar mais do que 5 vezes o volume do leito[2].

Outro factor importante na retenção/eluição do analito é o fluxo pelo qual a amostra e os outros solventes são veiculados através do enchimento. A velocidade do fluxo não deve ultrapassar $5-10 \mathrm{~mL} / \mathrm{min}$ por cada $100 \mathrm{mg}$ de enchimento a não ser no processo de troca-iónica onde o fluxo tem de ser mais lento não devendo ultrapassar nunca $5 \mathrm{~mL} / \mathrm{min}$ [3].

Se a retenção/eluição do analito não for a esperada e se o fluxo for a possível causa do problema, uma forma prática de verificar essa origem é deixar decorrer todo o processo apenas sob a acção da gravidade. Quando o processo de retenção/eluição não é conseguido apenas sob a força da gravidade, as causas não estão relacionadas com a velocidade do fluxo.

A capacidade avalia-se pela quantidade de analito e demais componentes/interferentes da amostra veiculados por um dado solvente, que é capaz de ser retida numa determinada massa de enchimento. A capacidade é expressa pela percentagem de componente retida em relação à massa total de enchimento, excepto para processos de troca-iónica onde é medida pelo número de equivalentes por grama de enchimento. Neste caso a capacidade varia entre $0,5 \mathrm{mEq} / \mathrm{g}$ a $1,5 \mathrm{mEq} / \mathrm{g}$ enquanto nos outros pode atingir máximos de $5 \%$ ou ficar-se por mínimos de $1 \%$. Quer isto dizer que, geralmente, 100 $\mathrm{mg}$ de enchimento podem reter, no máximo, $5 \mathrm{mg}$ de substância. No entanto não devemos esquecer de ter em conta não só o analito mas também, e sobretudo, a quantidade de componentes da matriz que fica retida conjuntamente com o analito, na determinação de quanto enchimento é necessário ao processo de extracção em causa $[2,4,5]$.

É claro que a utilização de grandes quantidades de enchimento resolveria estes problemas mas, para além do próprio custo do enchimento, a necessidade de grandes volumes de eluente resultaria num extracto final mais diluído, pelo que só a melhoria da selectividade ultrapassará estes inconvenientes.

A selectividade será então, a possibilidade que o enchimento tem de reter prioritariamente o analito pretendido entre os outros componentes da matriz. Um enchimento com elevada selectividade é aquele que retém apenas um componente da matriz e que será, obviamente, o analito [3].

\section{INTERACÇÕES \\ ENCHIMENTO/ANALITO:}

Em SPE é necessário ter em linha de conta as interacções químicas que se estabelecem entre o enchimento e o analito existente na solução a analisar uma vez que são elas que, em última instância, definem a retenção/eluição dos analitos. Os enchimentos, independentemente do seu grupo funcional, apresentam mais do que um tipo de interacção devido, fundamentalmente, aos sol- 
ventes utilizados. No entanto, as interacções enchimento/analito podem ser classificadas em seis grandes grupos: adsorção, apolares, polares, troca-iónica, covalentes e múltiplas.

\section{Adsorção}

As interacções devidas a mecanismos de adsorção podem ser definidas como aquelas que se estabelecem entre as moléculas de um soluto e a superfície de um sólido. Atendendo a que a quantidade de moléculas adsorvidas é directamente proporcional ao valor da superficie total do adsorvente, não será de estranhar que este seja, em geral, finamente dividido [6, 7].

$\mathrm{O}$ enchimento que melhor caracteriza este tipo de interacção é a terra de diatomáceas. Regra geral, este enchimento não é submetido a acondicionamento prévio sendo a amostra veiculada em solução aquosa que é totalmente absorvida pelo adsorvente. Só após a absorção da amostra pelo enchimento é que o eluente, geralmente constituído por solventes orgânicos, isolados ou em mistura, é adicionado.

Os solventes que mais favorecem a eluição com este tipo de mecanismo, são hexano, tolueno, clorofórmio, diclorometano, acetonitrilo, etanol e metanol [8].

Como nota final, e apesar de todos os tipos de enchimento possuírem propriedades adsorptivas, é de referir que, para além da terra de diatomáceas, o carvão, o florisil, a alumina e a sílica são, também, reconhecidos como enchimentos cujo principal mecanismo de interacção é a adsorção [9].

\section{Apolares}

Estas interacções são devidas às chamadas forças de van der Waals e estabelecem-se entre as ligações carbono-hidrogénio do analito e as do grupo funcional do enchimento uma vez que só na sílica ligada ocorre este tipo de interacções [3].

A ligação de octadecilsilano à sílica veio originar o mais popular enchimento até hoje conhecido, o C18, onde as interacções apolares são, por assim
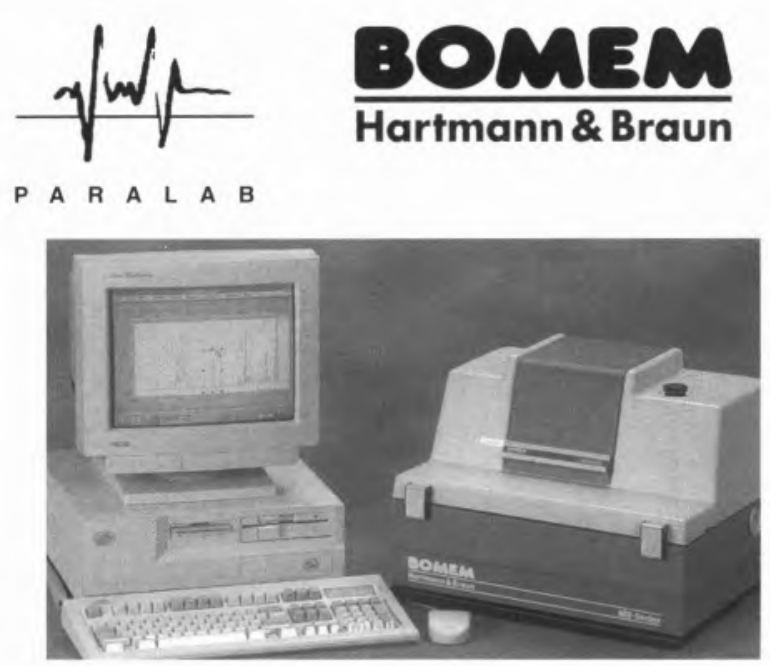

\section{Espectrometros FT-IR e FT-NIR}

PARALAB Rua do Bonjardim, 3724000 PORTO

Tel: (02) 2083223 Fax: (02) 2083247 E-mail: paralab@mail.telepac.pt

dizer, "raínhas e senhoras". No entanto, outros grupos funcionais há, onde as interacções apolares são, também, predominantes conforme o descrito na primeira parte desta revisão [1].

As interacções apolares entre enchimentos e analitos apolares estão facilitadas quando se usam solventes polares. A água é, aliás, o melhor exemplo do solvente capaz de facilitar a retenção devida a interacções apolares. Para além da água podem ainda ser considerados bons solventes de retenção a mistura de água com outros solventes, particularmente acetonitrilo e metanol e soluções-tampão com fraca força-ióni$\mathrm{ca}$, inferior a $0,1 \mathrm{M}$.

Por outro lado o rompimento das ligações estabelecidas por mecanismos apolares só pode ser efectuado por eluentes não polares, ainda que em pequena escala [10]. Para muitos analitos, mesmo um solvente como o acetonitrilo apresenta sufici- entes caracteristicas apolares para conseguir romper a interacção apolar estabelecida entre o analito e o enchimento e, assim, originar a eluição do primeiro.

No entanto, quanto mais apolar for o analito, maior será a necessidade de utilizar um eluente com características apolares como sejam metanol, acetato de etilo, clorofórmio, tetra-hidrofurano, diclorometano e, mesmo, hexano [2]. Contudo, a combinação entre dois ou mais solventes começa a ser bastante utilizada como forma de alcançar o mais selectivo eluente para um dado analito retido num determinado enchimento.

Em resumo, podemos afirmar que a retenção de analitos por mecanismos apolares é facilitada por solventes polares, enquanto a eluição de analitos de enchimentos apolares é melhor conseguida por solventes ou misturas de solventes com características apolares. 


\section{Polares}

As interacções polares ocorrem entre os grupos reactivos do analito capazes de apresentarem momentos dipolares e os grupos funcionais do enchimento com semelhantes caracteristicas. Além das ligações dipolo-dipolo, naturais ou induzidas, são também incluídos, nas interacções polares, as ligações por pontes de hidrogénio e toda uma variedade de outros mecanismos capazes de conferir um comportamento polar, positivo ou negativo, aos grupos reactivos quer do analito quer do enchimento. Entre os grupos capazes de apresentar este tipo de comportamento é comum referiremse hidroxilos, aminas, carbonilos, anéis aromáticos, sulfidrilos, duplas ligações e grupos que contenham hetero-átomos como oxigénio, azoto, enxofre ou fósforo [3].

A natureza polar da sílica, e especialmente dos grupos silanol livres, origina que em todas as bases de sílica ligada sejam evidentes as características de interações polares. Estas interações polares secundárias devidas à sílica são tanto mais importantes quanto mais apolar for o solvente.

As interações polares entre os grupos funcionais do enchimento e os do analito são facilitadas por solventes apolares. Por outro lado este tipo de interações são mais facilmente suprimidas por solventes polares. Quer isto dizer que como solventes que facilitam a retenção com estes mecanismos, temos hexano, isooctano, diclorometano, tetra-hidrofurano, clorofórmio e acetato de etilo, embora estes três últimos só quando estão em causa analitos muito polares. Analogamente, os solventes que facilitam a eluição são água, solventes de elevada força iónica, ácido acético, actetonitrilo, acetona, metanol e isopropanol. As misturas de um ou mais dos solventes indicados são, também, bastante utilizadas como forma de melhorar quer a retenção quer a eluição [2].

Em resumo, a retenção de analitos por mecanismos polares é facilitada por solventes apolares, enquanto a eluição de analitos de enchi- mentos polares é melhor conseguida por solventes polares. Os analitos polares, particularmente se contêm grupos hidroxilo ou amina, podem ser retidos nos enchimentos apolares de base de sílica por interacções polares secundárias.

\section{Troca-iónica}

As interacções iónicas dão-se entre um analito portador de carga, seja ela positiva ou negativa, e o enchimento com uma carga oposta. Duma forma geral, este género de interacções pode ser dividido em duas classes distintas: catiónicas e aniónicas.

Como exemplo de analitos que podem apresentar interacções de troca catiónica, são referidos as moléculas cujo grupo funcional é capaz de exibir carga positiva, por exemplo grupos básicos, aminas primárias, secundárias, terciárias e quaternárias, e, também, catiões inorgânicos como cálcio, sódio e magnésio. Nas interacções de troca-aniónica podem incluir-se os exemplos de analitos cujo grupo funcional é capaz de apresentar carga negativa como sejam os grupos ácidos carboxilico, sulfónico e fosfórico e aniões inorgânicos como os sulfatos, cloretos e nitratos [11].

No entanto, a carga da grande maioria dos grupos iónicos está dependente do $\mathrm{pH}$ do solvente em que se encontra. Assim, torna-se necessário conhecer qual o pKa de cada grupo iónico para saber se as moléculas apresentam ou não carga. Como se sabe, o número de moléculas com carga positiva aumenta quando se encontram num solvente com $\mathrm{pH}$ inferior ao seu pKa e diminui com valores de $\mathrm{pH}$ superiores ao pKa. Inversamente, o número de moléculas com carga negativa é maior em solventes com $\mathrm{pH}$ acima do seu pKa e diminui para valores de $\mathrm{pH}$ abaixo do $\mathrm{pKa}$.

A retenção, neste caso, ocorre quando o $\mathrm{pH}$ do solvente/matriz permite que o analito e o enchimento estejam carregados, ou seja, o $\mathrm{pH}$ do solvente/matriz inferior ao pKa do analito para catiões e inverso para aniões. Os valores ideais de $\mathrm{pH}$, onde cerca de $99 \%$ das moléculas do analito se apresentam carregadas, podem ser definidos em relação ao $\mathrm{pKa}$ da seguinte forma: $\mathrm{pH}=\mathrm{pKa}-2$ para catiões e $\mathrm{pH}=\mathrm{pKa}+2$ para aniões. A eluição, pelo contrário, está facilitada quando se eleva o $\mathrm{pH}$ acima do $\mathrm{pKa}$, no caso dos grupos catiónicos, ou quando se diminui o $\mathrm{pH}$ abaixo do pKa, no caso dos grupos aniónicos. Quer num caso quer no outro, a remoção do analito dá-se devido ao facto de os grupos funcionais passarem a estar neutros em vez de carregados. A retenção/eluição, neste tipo de mecanismo, é, também, afectada pela força iónica do solvente/matriz e pela selectividade do enchimento, enquanto os eluentes devem possuir uma forte força iónica com contra-iões de elevada selectividade para o enchimento $[2,5]$.

Resumindo, consideram-se bons solventes de retenção, a água e tampões de fraca força iónica, inferior a $0,1 \mathrm{M}$, com pHs abaixo do valor de $\mathrm{pKa}$ do enchimento e acima do $\mathrm{pKa}$ do analito, respectivamente para mecanismos de troca aniónica e catiónica. Bons solventes de eluição, neste tipo de mecanismo, são aqueles que se encontram no quadro I.

A selectividade do contra-ião existente no enchimento pode ser alterada da seguinte forma:

- Quando se pretende mudar para um contra-ião de elevada selectividade, faz-se passar pelo enchimento, 2 a 5 vezes o volume do seu leito, uma solução $1 \mathrm{~N}$ do contra-ião desejado;

- Quando o objectivo é mudar para um contra-ião de baixa selectividade, divide-se a selectividade existente pela do que se pretende introduzir. O quociente é multiplicado por 5 e o produto encontrado é o número de volumes de leito, que tem de ser passados pelo enchimento, da solução que contém o contraião pretendido na concentração $1 \mathrm{~N}$.

As alterações de contra-ião são tanto mais eficientes quanto menor for a velocidade do fluxo pelo qual as soluções do contra-ião são veiculadas através do enchimento. Como por exemplo, recomenda-se que o referi- 
do fluxo não exceda nunca $5 \mathrm{~mL} / \mathrm{min}$ por $100 \mathrm{mg}$ de enchimento [5].

A exemplo do que já se disse anteriormente também todas as bases de sílica ligadas apresentam interacções iónicas secundárias. As aminas são o grupo funcional mais afectado por este tipo de interacções secundárias. $\mathrm{O}$ rompimento desta interacção pode ser conseguido, como já vimos, por uma alteração de $\mathrm{pH}$. Valores de $\mathrm{pH}$ elevados conduzem a uma amina neutra, enquanto a utilização de solventes com baixo valor de $\mathrm{pH}$ levam à neutralização do grupo silanol. A utilização de solventes adicionados de outro tipo de amina, dietil ou trietil, constitui, também, um processo alternativo conducente ao rompimento deste tipo de interacção.

\section{Covalentes}

As interacções covalentes são o resultado de uma ligação química com o mesmo nome que se estabelece entre o enchimento e o analito $[10,12]$.

Se tivermos em linha de conta que o carbono e o silício são os elementos mais propícios à formação de ligações covalentes e que estas são, mesmo, as interacções que envolvem maior energia entre as já descritas [13], rapidamente concluiremos que este tipo de interacção é bastante selectiva, conhecendo-se apenas um enchimento, ácido fenilborónico, onde estas interacções ocorrem como mecanismo primário [1].

A capacidade deste tipo de enchimento depende do $\mathrm{pH}$. Uma vez que o $\mathrm{pH}$ do ácido fenilborónico ronda o valor de 9.2, não será de estranhar que os solventes utilizados para melhorar a retenção, através de interacções covalentes, sejam soluções alcalinas com valores de $\mathrm{pH}$ entre 10 e 12. Analogamente, os ácidos acético, fórmico, fosfórico e trifluoracético constituem o melhor grupo de eluentes, quando estão em jogo estas interacções [14].

As interacções covalentes são utilizadas, em SPE, como primárias em analitos que contenham grupos diol vicinais na sua estrutura quími-

\section{Tituladores Automáticos}
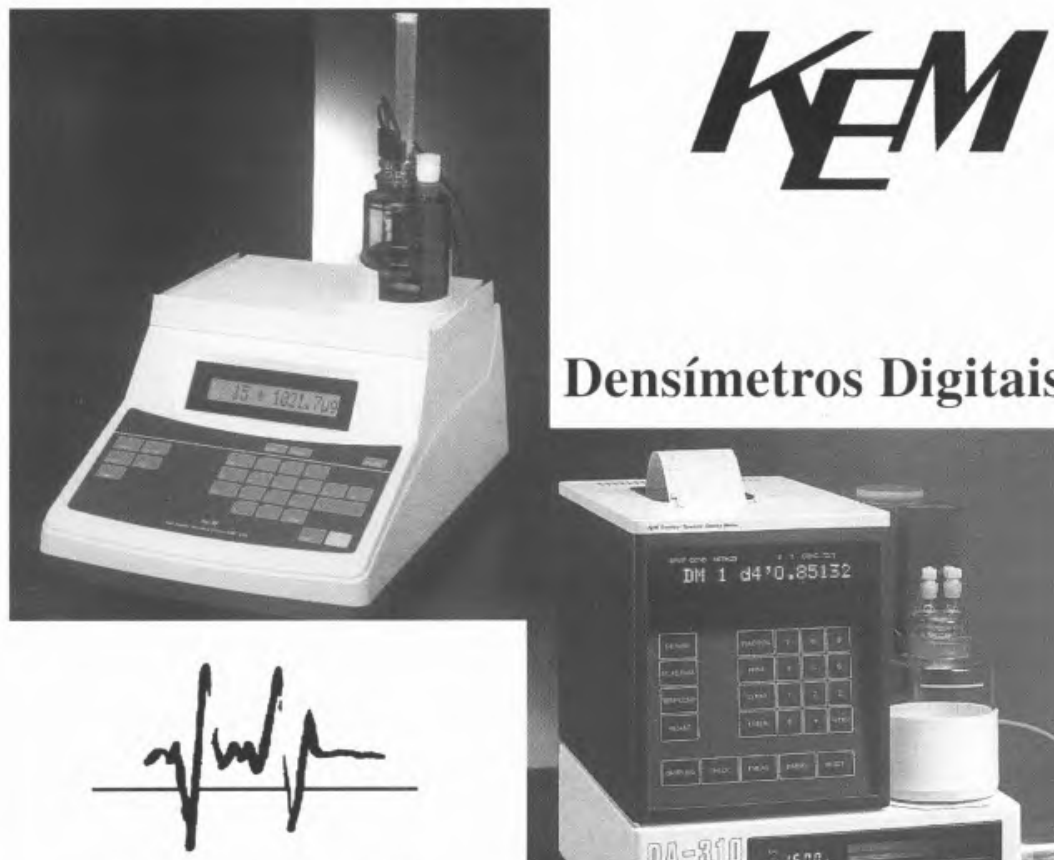

P A R A L A B

\section{Densímetros Digitais}

Rua do Bonjardim, 3724000 PORTO

Tel: (02) 2083223 Fax: (02) 20883247 E-mail: paralab@mail.telepac.pt

ca [10]. No entanto, apesar deste tipo de mecanismo não ser utilizado como principal na retenção/eluição da maior parte dos analitos, não podemos excluir a sua ocorrência como secundário, ainda que não desejado, nos outros tipos de enchimento.

\section{Múltiplas}

Como já tivemos oportunidade de verificar, e embora para cada tipo de enchimento/analito haja um mecanismo predominante, constata-se que, sobretudo quando se utilizam as bases de sílica ligada, estão quase sempre em jogo mais do que um tipo de interacções.

As interacções múltiplas, porém e para além de ocorrerem naturalmente, são, muitas vezes, pretendidas como se verifica com os enchimentos que são uma mistura de grupos apolares com iónicos, sejam eles catiónicos ou aniónicos, "de per si" ou conjuntamente [15, 16].

Os solventes que facilitam a retenção com este tipo de interacções são, sobretudo, tampões cujo pH é defenido de acordo com o enchimento e com o pKa dos analitos a extrair/purificar. A eluição é, normalmente, conseguida com uma mistura de um solvente orgânico com hidróxido de amónio preparada imediatamente antes de usar através de agitação vigorosa pelo período de um minuto ou ultrasons durante cinco minutos, devido à rápida evaporação do hidróxido de amónio [17, 18].

\section{INTERACÇÕES ANALITO /MATRIZ}

As propriedades da matriz, como $\mathrm{pH}$, carácter polar ou apolar, força iónica, entre outros, influenci- 
am, também, a retenção do analito podendo-a aumentar, diminuir, ou mesmo inibir, consoante o mecanismo em causa.

A diluição da matriz é, muitas vezes, suficiente para alterar as referidas propriedades e permitir uma correcta retenção.

No entanto, nesta área, existem duas interacções que se podem considerar importantes: a adsorção do analito à matriz quando esta é sólida $e$ as ligações do analito às proteinas da matriz. A primeira dá origem a percentagens de recuperação de analito reduzidas e pode ser ultrapassada através de extracção do analito da matriz inicial com solventes de elevada solubilidade para o mesmo ou utilizando métodos de extracção eficientes como, por exemplo, Soxhlet ou ultrasons [19, 20].

A ligação do analito às proteinas da matriz, quando ocorre, faz-se através da parte activa da molécula que é, também, aquela que reage com o grupo funcional do enchimento. Correntemente, existem dois processos de libertar o analito da sua ligação à proteína:

- Alterar o pH da amostra, uma vez que a maior parte destas ligações depende do $\mathrm{pH}$;

- Promover a eliminação da proteína por ultrafiltração ou por desnaturação/precipitação [21]. Esta última pode ser feita utilizando quatro princípios diferentes: ácidos, bases azotadas, solventes orgânicos ou catiões metálicos. Os compostos mais utilizados nestes processos são ácidos fórmico, sulfossalicílico, tricloroacético e perclórico, bases azotadas como a ureia, cloreto de guanidina ou sulfato de amónio, metanol ou acetonitrilo como solventes orgânicos e o acetato de chumbo como melhor catião metálico para este fim [22, 23].

Regra geral, pode suspeitar-se duma interacção analito/matriz quando no desenvolvimento do método se obtém uma boa retenção com o padrão que não se consegue reproduzir com a matriz adicionada de padrão.

\section{INTERACÇÕES MATRIZ/ ENCHIMENTO}

Este tipo de interacçōes ocorre quando alguns componentes da matriz apresentam características quimicas idênticas às do analito. Neste caso duas soluções são possíveis para resolver o problema:

- Escolher um mecanismo de extracção que não seja compartilhado simultaneamente pelos componentes da matriz e do analito. Por exemplo, se o analito apresenta propriedades apolares e iónicas deve escolher-se um mecanismo apolar quando a matriz apresenta elevado conteúdo em sais que iria interferir com uma extracção por troca-iónica [24];

- Remover, selectivamente, os componentes da matriz que possam interferir. No caso de utilizarmos um mecanismo de extracção apolar, devemos, por exemplo, submeter previamente a amostra ao Soxhlet para eliminar a gordura, componente que iria interferir com o mencionado mecanismo.

\section{CONCLUSÃO}

A exemplo da primeira parte deste trabalho, também agora não pretendemos ser exaustivos na abordagem que fizemos dos mecanismos de extracção que podem estar envolvidos num processo de SPE. No entanto, pensamos que o que atrás ficou escrito permitirá que qualquer potencial utilizador possa, à partida e uma vez conhecedor das propriedades do analito, escolher o enchimento adequado à realização do seu processo de extraç̧ão/purificação[1], bem assim como os solventes necessários à optimização da retenção e da eluição, em função dos mecanismos de extracção envolvidos.

Numa próxima publicação será feita a abordagem do desenvolvimento do método de forma a que os aspectos práticos da SPE venham a dar sequência aos aspectos teóricos já referidos e assim permitir aumentar o número de utilizadores que beneficiam das vantagens desta técnica.
Quadro I - Propridades ideais de eluentes para troca-iónica

\begin{tabular}{ll}
\hline Troca Aniónica & Troca Catiónica \\
\hline $\mathrm{pH}>\mathrm{pKa}+2$ do enchimento & $\mathrm{pH}<\mathrm{pKa}-2$ do enchimento \\
$\mathrm{pH}<\mathrm{pKa}-2$ do analito & $\mathrm{pH}>\mathrm{pKa}+2$ do analito \\
Força lónica $>0,1 \mathrm{M}$ \\
Possuir Contra-lão de Elevada Selectividade \\
Qualquer Combinação dos anteriores
\end{tabular}

* Laboratório de Bromatologia

Faculdade de Farmácia

Universidade de Coimbra - 3000 Coimbra

\section{BIBLIOGRAFIA}

1. M. C. Castilho, F. Ramos e M. I. N. Silveira, Quimica, submetido para publicaçào.

2. K. C. Van Horne, Sorbent Extraction Technology, Analytichem International, Harbor City, 1990.

3. M. Moors, D. L. Massart and R.D. McDowall, Pure \& Appl. Chem., 66 (1994) 277.

4. Macherey-Nagel, Sample Preparation with Chromabond and Chromatil@, Düren, 1994

5. I \& W Scientific, Chromatography Catalog \& Reference Guide, Folsom, 1994.

6. V. Alexéev, Análise Quantitativa, Lopes da Silva Editora, Porto, 1979.

7. A. I. L. O. Pombeiro, Técnicas e Operaçôes Unitárias en Quimica Laboratorial, Fundação Calouste Gulbenkian, Lisboa, 1983 .

8. L.R. Snyder, I. Chromatogr., 92 (1974) 223.

9. L.R. Snyder, Principles of Adsorption Chromatography, Marcel Dekker, New York, 1968.

10. R.D. McDowall, I.C. Pearce, and G.S. Murkitt, I. Pharm Biomed. Anal., 4 (1986) 3.

11. R. Anderson, Sample Pretreatment and Separation, N.B. Chapman (ACOL), John Wiley \& Sons, London, 1987.

12. D.D. Blevins, Analytichem International, M567.

13. R.D. McDowall, LC.GC Int., 7 (1994) 638.

14. M. L. Stolowitz, Analytichem International, M1843.

15. X. Chen, I. Wijsbeek, J. van Veen, J.P. Franke and R.A. de Zeeuw, J. Chromatogr., 529, (1990) 161.

16. X. Chen, I. Wijsbeek, I.P. Franke and R.A. de Zeeuw, I. Forensic Sci., 37 (1992) 61.

17. Analytichem International, M797.

18. M.P. Montrade, B, le Bizec and F. André, Document LDH/93/06 Nantes, 1993

19. M.P. Montrade, B. le Bizec and F. André, Document IDH/93/07 Nantes, 1993.

20. F. Ramos, M.C. Castilho and M.I.N. Silveira, EuroResidue II - Conference of Veterinary Drugs in Food, N. Haagsma, A. Ruiter and P.B. Czedik-Eysenberg, Veldhoven, 1993.

21. R.D. McDowall, E. Doyle, G.S. Murkitt and V.S. Picot, I. Pharm. Biomed. Anal., 7 (1989) 1087.

22. Nilsson-Ehle, J.Liq.Chromatogr., 6 (1983) 251.

23. H.M. Liebich, Anal.Chim.Acta, 236 (1990) 121.

24. K.C. van Horne, Analytichem International, M658. 


\section{Contrariamos a tradição ... ... fazemos \\ Depressa e Bem!

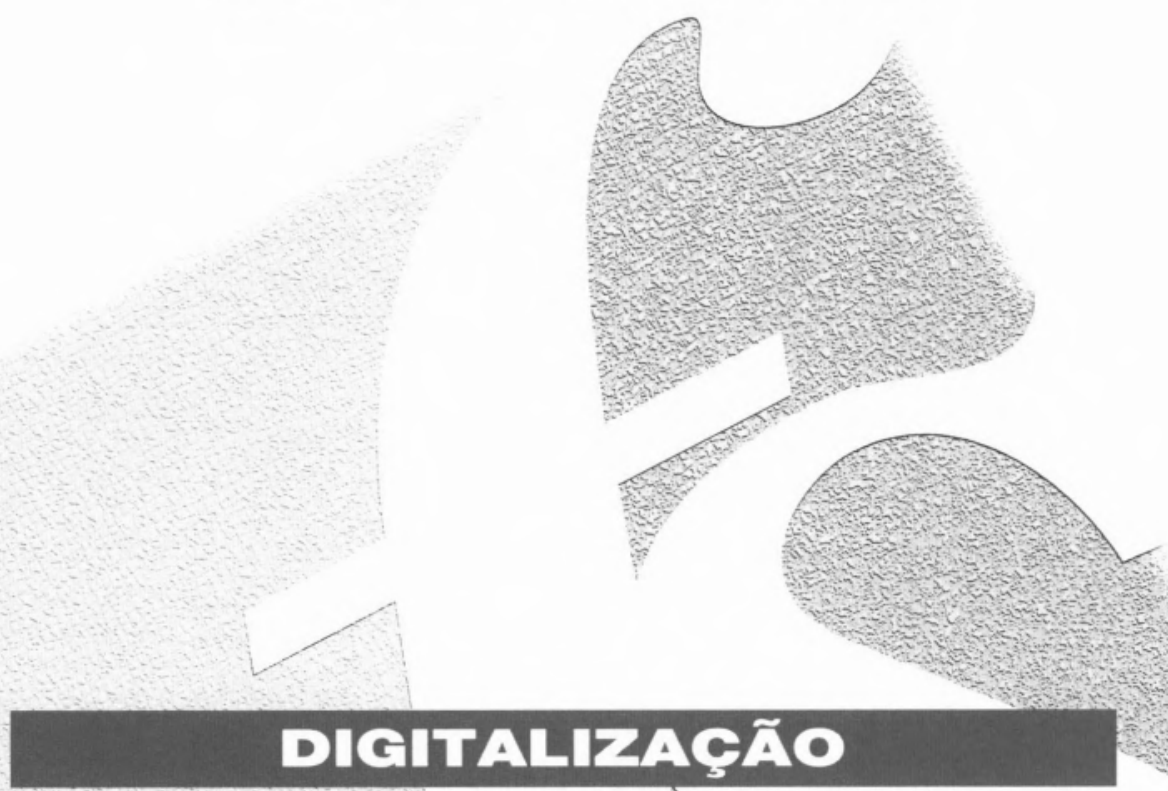

\section{TRATAMENTO DE IMAGEM}

\section{PRÉ-IMPRESSÃo}

\section{IMPRESSÃO}

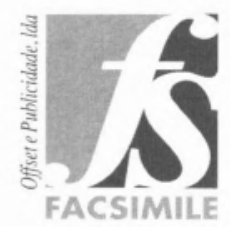

Rua dos Lagares D'El Rei, Lote 1481 R/C Dto. • 1700 LISBOA 